\title{
Ablation Resolution in Laser Corneal Refractive Surgery: The Dual Fluence Concept of the AMARIS Platform
}

\author{
Samuel Arba-Mosquera ${ }^{1,2}$ and Thomas Hollerbach ${ }^{1}$ \\ ${ }^{1}$ Research and Development Department, SCHWIND Eye-Tech-Solutions, 63801 Kleinostheim, Germany \\ ${ }^{2}$ Grupo de Investigación de Cirugía Refractiva y Calidad de Visión, Instituto de Oftalmobiología Aplicada, \\ University of Valladolid, 47011 Valladolid, Spain
}

Correspondence should be addressed to Samuel Arba-Mosquera, samuel.arba.mosquera@eye-tech.net

Received 15 February 2010; Revised 21 June 2010; Accepted 8 July 2010

Academic Editor: Maria Calvo

Copyright (C) 2010 S. Arba-Mosquera and T. Hollerbach. This is an open access article distributed under the Creative Commons Attribution License, which permits unrestricted use, distribution, and reproduction in any medium, provided the original work is properly cited.

Purpose. To evaluate to which extent individual Zernike terms can be corrected. Methods. Ablation time and fidelity was analysed using different fluence levels (range $90-2000 \mathrm{~mJ} / \mathrm{cm}^{2}$ ) and aspheric ablation profiles. With optimal parameters, the extent to which individual Zernike modes can be corrected was evaluated. Results. The range $188-565 \mathrm{~mJ} / \mathrm{cm}^{2}$ resulted as optimum fluence level with an optimum proportion range 50\%-90\% for high fluence. With optimal parameters, it corresponds to $2.4 \mathrm{~s} / \mathrm{D}$ at $6 \mathrm{~mm}$ OZ, with fidelity variance of $53 \mu \mathrm{m}$ RMS, and average ablation error of $0.5 \mu \mathrm{m}$ for each location. Ablation simulation of coma Z[3, \pm 1$]$ showed 98,4\% accuracy and 98\% fit quality; trefoil Z[3, \pm 3$], 99,9 \%$ accuracy and 98\% fit quality; spherical aberration Z[4,0], $96,6 \%$ accuracy and $97 \%$ fit quality; secondary astigmatism $Z[4, \pm 2], 97,9 \%$ accuracy and $98 \%$ fit quality. Real ablation on a flat plate of PMMA of coma Z[3, \pm 1$]$ showed $96,7 \%$ accuracy and $96 \%$ fit quality; trefoil $Z[3, \pm 3], 97,1 \%$ accuracy and $96 \%$ fit quality; spherical aberration Z[4,0], with $93,9 \%$ accuracy and $90 \%$ fit quality; secondary astigmatism Z[4, \pm 2$]$, with $96,0 \%$ accuracy and $96 \%$ fit quality. Conclusions. Ablation of aspherical and customised shapes based upon Zernike polynomials up to the the 8 th order seems accurate using the dual fluence concept implemented at the AMARIS platform.

\section{Introduction}

With the introduction of the laser technologies for refractive surgery, the change of the corneal curvature to compensate in a controlled manner for refractive errors of the eye [1] is more accurate than ever. The procedure is nowadays a successful technique, due to its submicrometric precision and the high predictability and repeatability of corneal ablation accompanied by minimal side effects. Standard ablation profiles based on the removal of convex-concave tissue lenticules with spherocylindrical surfaces proved to be effective in the compensation of primary refractive errors. However, the quality of vision deteriorated significantly, especially under mesopic and low-contrast conditions [2].

With the introduction of wavefront analysis, it was proved that the conventional refractive LASER techniques were far from ideal, by measuring the aberrations induced by conventional algorithms and the aberrations induced by the LASIK flap cut itself.

With the LASIK (Laser in Situ Keratomileusis [3]) treatment, we have an accepted method to correct refractive errors such myopia [4], hyperopia [5], and astigmatism [6]. One of the most significant side effects in myopic LASIK, is the induction of spherical aberration [7], which causes halos and reduced contrast sensitivity [2]. However, the different laser platforms are always introducing new concepts and optimising their ablation profiles.

Since Laser refractive surgery was introduced, the technology rapidly improved. With the beginning of photoablation, the goal was to achieve predictable and stable results for myopic, hyperopic, and astigmatic corrections. Today's technology is far more advanced since sophisticated diagnostic instruments, such as aberrometers and topography systems, offer the challenge of improving the postoperative 


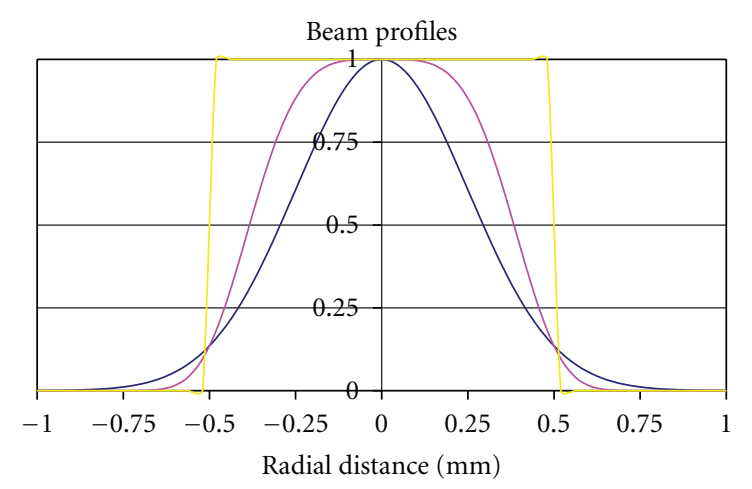

$\begin{aligned} N & =1 \text { gaussian } \\ N & =2 \\ N & =\infty \text { flat-top }\end{aligned}$

Figure 1: Beam profiles for different beam geometries. Gaussian profile in blue, supergaussian profile $(N=2)$ in pink, Flat-Top profile in yellow.

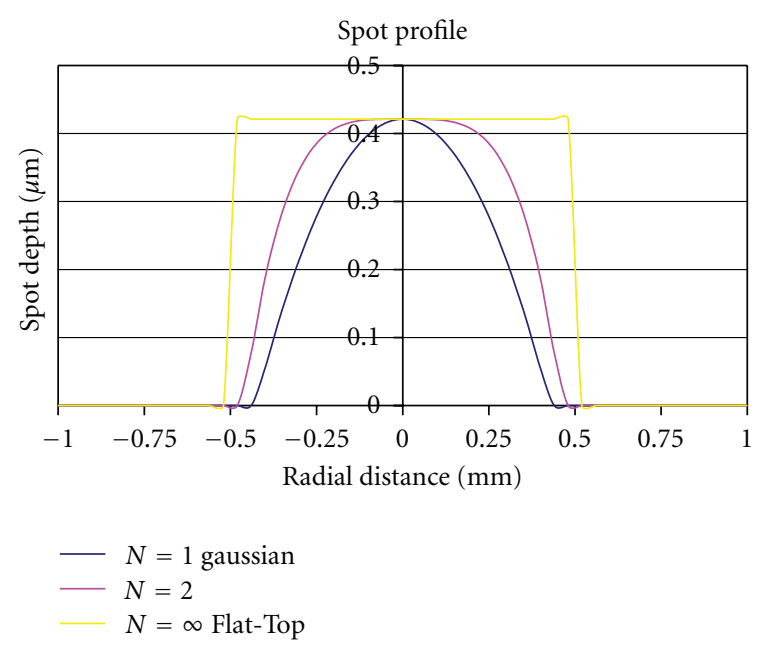

Figure 2: Spot profiles for different beam geometries. Parabolic spot profile (from Gaussian beams) in blue, quartic spot profile (from supergaussian $(N=2)$ beams) in pink, Flat-Top spot profile (from Flat-Top beams) in yellow.

results in terms of visual acuity and night vision. At the same time, the better knowledge and understanding on refractive surgery by potential patients upgrades the required standard outcomes. Making more challenge finding new approaches towards the close-to-zero aberrations target results in several senses: (a) finding the sources of the induced aberrations due to laser refractive surgery, (b) developing "free-ofaberrations" ablation profiles, (c) developing ablation profiles to compensate the natural aberrations of any single eye in order to get a close-to-zero aberrations result.

To eliminate already existing aberrations, the so-called "customized" treatments were developed. Customisation of

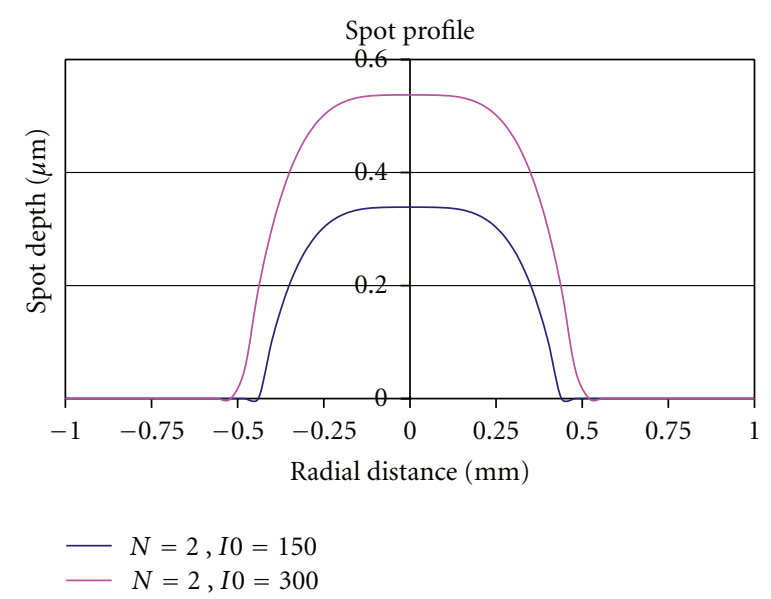

FIGURE 3: Spot profiles for different radiant exposures. Quartic spot profiles (from supergaussian $(N=2)$ beams) for a peak radiant exposure of $150 \mathrm{~mJ} / \mathrm{cm}^{2}$ in blue and for a peak radiant exposure of $300 \mathrm{~mJ} / \mathrm{cm}^{2}$ in pink.

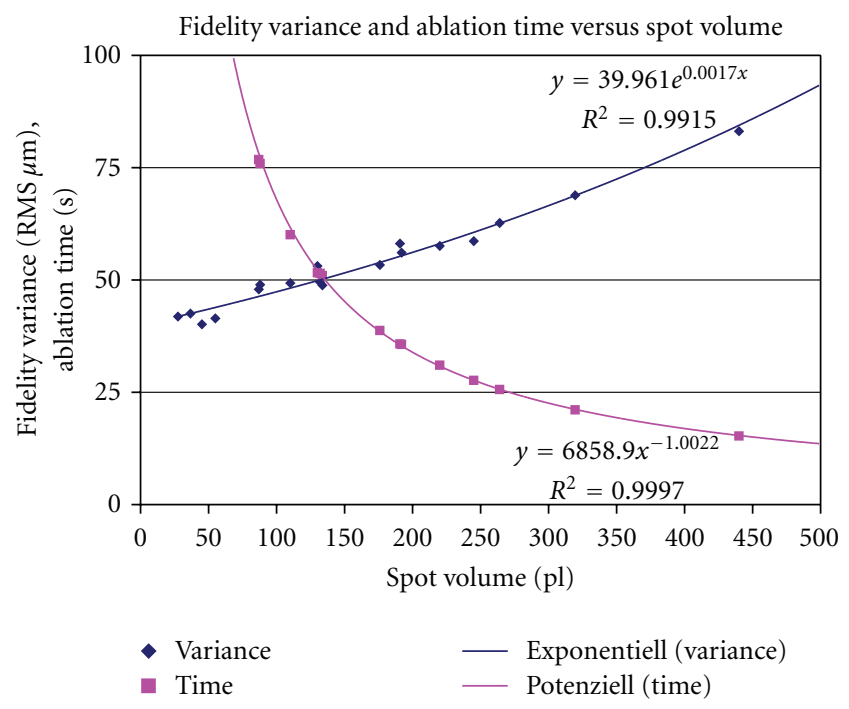

FIgURE 4: Fluence simulation results.

the ablation is possible either using wavefront measurements of the whole eye [8] (obtained, e.g., by HartmanShack wavefront sensors) or by using corneal topographyderived wavefront analyses $[9,10]$. Topographic-guided [11], Wavefront-driven [12], Wavefront-optimized [13], Asphericity preserving, and Q-factor profiles [14] have all been put forward as solutions. Nevertheless, considerations such as treatment duration, tissue removal [15], tissue remodelling, and overall postoperative outcomes have made it difficult to establish a universal optimal profile.

Therefore, the topic "ablation resolution in laser corneal refractive surgery" is still worth to be analysed and considered, because its clinical implications are not yet deeply explored.

The real impact of ablation resolution in laser corneal refractive surgery is still discussed in a controversial way. The 


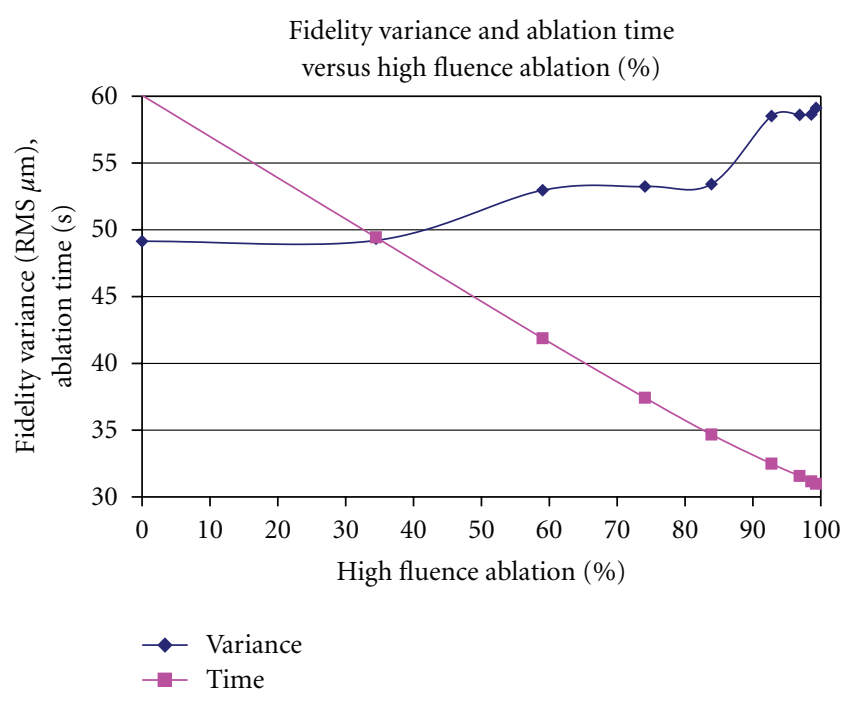

FIGURE 5: Dual fluence simulation results.

TABLE 1: AMARIS decision: single fluence concept.

\begin{tabular}{lcc}
\hline Metric & High fluence & Low fluence \\
\hline Fluence $(\mathrm{pl})$ & 220 & 110 \\
Energy density $\left(\mathrm{mJ} / \mathrm{cm}^{2}\right)$ & 488 & 197 \\
Ablation time $(\mathrm{s})$ & 31 & 60 \\
Ablation time $(\mathrm{s} / \mathrm{D}$ at $6 \mathrm{~mm}$ OZ) & 2.1 & 4.0 \\
Fidelity variance $(\mu \mathrm{m}$ RMS) & 60 & 50 \\
Ablation error $(\mu \mathrm{m}$ for each location $)$ & 0.575 & 0.475 \\
\hline
\end{tabular}

aim of this work is to provide a simple and understandable theoretical frame explaining a possible method of ablation resolution optimisation.

Most of the systems available for laser refractive surgery include possibilities to customise the ablation, either based on topographical elevation or on corneal or ocular wavefront aberration.

\section{Materials}

To evaluate the technical capabilities to correct individual Zernike modes, and the extent to which individual Zernike modes can be corrected, the CAM software was used to plan the ablations, which were first simulated and then ablated onto flat PMMA plates with an AMARIS excimer laser (SCHWIND eye-tech-solutions GmbH, Kleinhostheim, Germany).

The AMARIS laser system works at a repetition rate of $500 \mathrm{~Hz}$, produces a spot size of $0.54 \mathrm{~mm}$ (full width at half maximum (FWHM)) with a superGaussian ablative spot profile [16, 17]. High-speed eye-tracking with $1050 \mathrm{~Hz}$ acquisition rate is accomplished with 3-ms latency period [18]. The system delivers aspheric wavefront-customised profiles and including some optimisations: The aspheric
TABLE 2: AMARIS decision: dual fluence concept.

\begin{tabular}{lcc}
\hline Metric & $\begin{array}{c}\approx 80 \% \text { High } \\
\text { fluence }\end{array}$ & $\begin{array}{c}+20 \% \text { Low } \\
\text { fluence }\end{array}$ \\
\hline Fluence $(\mathrm{pl})$ & 220 & 110 \\
Energy density $\left(\mathrm{m} J / \mathrm{cm}^{2}\right)$ & 488 & 197 \\
Ablation time $(\mathrm{s})$ & 35 & \\
Ablation time $(\mathrm{s} / \mathrm{D}$ at $6 \mathrm{~mm}$ OZ) & 2.4 & \\
Fidelity variance $(\mu \mathrm{m}$ RMS $)$ & 53 & \\
Ablation error $(\mu \mathrm{m}$ for each location $)$ & 0.500 & \\
\hline
\end{tabular}

profiles go beyond the Munnerlyn proposed profiles, and add some aspheric characteristics to balance the induction of spherical aberration (prolateness optimisation).

These particular case of aspheric profiles compensate for the aberrations induction observed with other types of profile definitions [19], some of those sources of aberrations are those ones related to the loss of efficiency of the laser ablation for nonnormal incidence [20-22].

Optimisation consisted to take into account the loss of efficiency at the periphery of the cornea in relation to the centre as there is a tangential effect of the spot in relation to the curvature of the cornea (Keratometry (K-reading)). The software provides K-reading compensation, which considers the change in spot geometry and reflection losses of ablation efficiency.

An optical zone of $6.50 \mathrm{~mm}$ in diameter was planned, a variable transition zone, to smooth the ablated area towards the nontreated cornea, was provided automatically by the software in relation to the refraction to be corrected.

Real ablative spot shape (volume) is considered through a self-constructing algorithm. In addition, there is a randomised flying-spot ablation pattern, and controls the local repetition rates to minimise the thermal load of the treatment [23] (smooth ablation, no risk of thermal damage). Therefore, the ablated surface after aspheric wavefrontcustomised profiles is very smooth, so that there are some benefits in higher order aberrations.

\section{Method}

Laser corneal refractive surgery is based on the use of a Laser (typically an excimer one) to change the corneal curvature to compensate for refractive errors of the eye. It has become the most successful technique, mainly due to the submicron precision and the high repeatability of the ablation of the cornea accompanied by minimal side effects. Laser refractive surgery is based upon the sequential delivery of a multiplicity of laser pulses each one removing (ablating) a small amount of corneal tissue.

From the blowoff model (derived form the BeerLambert's law), the real energy density absorbed at that point determines the ablation depth as

$$
d_{i j}=\frac{\ln \left(I_{i j}\left(1-R_{i j}\right) / I_{\mathrm{Th}}\right)}{\alpha_{\text {Cornea }}},
$$




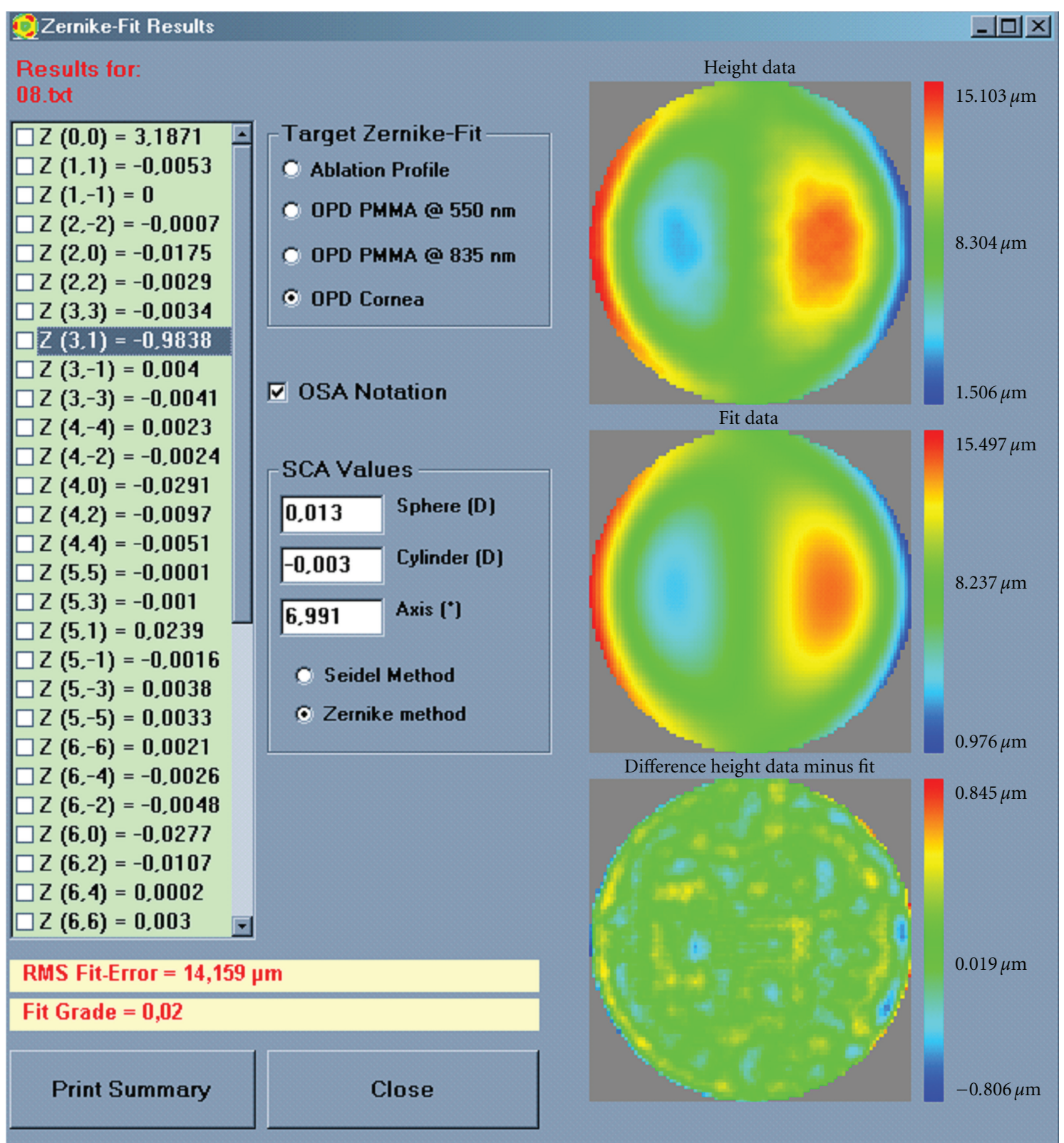

FIGURE 6: Ablation simulation of primary coma aberration $Z[3, \pm 1]$, with $98,4 \%$ accuracy and $98 \%$ fit quality.

where $d_{i j}$ is the actual depth per pulse at the location $i, j ; I_{i j}$ is the radiant exposure of pulse at the location $i, j ; R_{i j}$ is the reflectivity at the location $i, j ; I_{\mathrm{Th}}$ is the corneal threshold; $\alpha_{\text {Cornea }}$ is the corneal absorption coefficient.

In general,

$$
d(r)=\frac{\ln \left(I(r)(1-R(r)) / I_{\mathrm{Th}}\right)}{\alpha_{\text {Cornea }}}
$$

For different beam profiles we get different spot profiles as depicted in Figures 1 and 2.
For different radiant exposures with the same beam profiles, we get different spot profiles as displayed in Figure 3.

The problem of the spot profile and the radiant exposure of the system relies on the sequential delivery of a multiplicity of laser pulses each one ablating locally a small amount of corneal tissue, being the global process an integral effect. The higher the spot profile is, the higher the ablated volume per pulse limiting the resolution of the treatment.

There are several ways to avoid that problem.

(i) Reducing the radiant exposure improving the vertical resolution of the treatment.

(ii) Reducing the spot diameter improving the horizontal resolution of the treatment. 


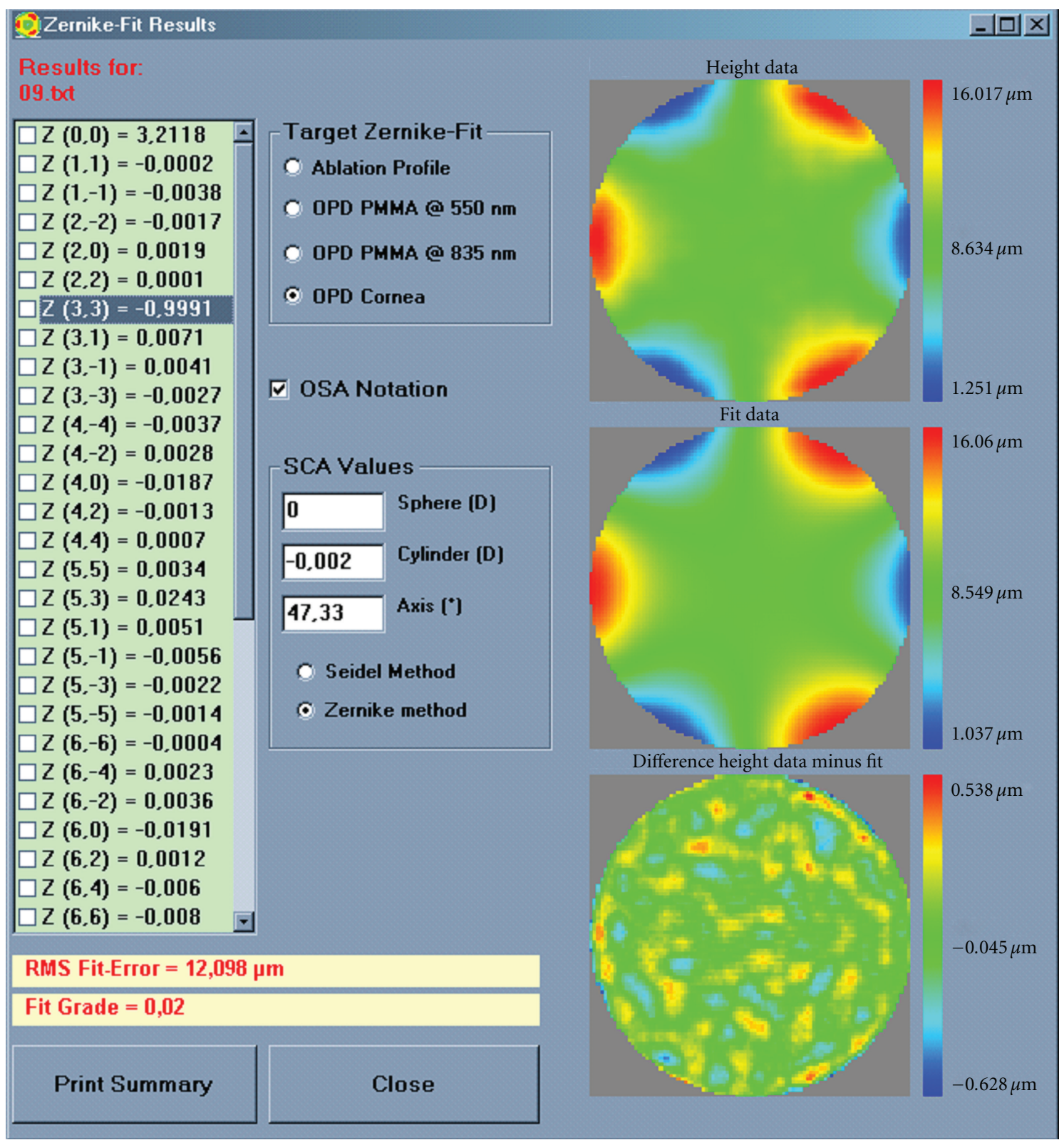

FIgURE 7: Ablation simulation of primary trefoil aberration $Z[3, \pm 3]$, with $99,9 \%$ accuracy and $98 \%$ fit quality.

The problem of both alternatives is that they need extra time for the ablation procedure, which may produce another inconveniences.

The gained ablation volume has to be applied onto the cornea by thousands of single laser shots at different but partly repeated corneal positions, because the ablated volume of a single spot is much smaller than the ablation volume.

We have introduced as well some innovations concerning ablation shot file (sequences of pulses needed to carry out a refractive procedure) generation, in order to optimally remove the tissue corresponding to these state-of-the-art treatments, generating the sequence of laser shot coordinates in a way that (i) guarantees a high fidelity reproduction of the given ablation volume line shape and

(ii) avoids vacancies and roughness of the cornea.

In this context, two opposed requirements define the fluence level.

(i) A short ablation time (favouring high fluence levels).

(ii) A high-fidelity ablation (favouring low fluence levels).

We have analysed ablation times and fidelity using fixed fluence levels ranging from $37 \mathrm{pl}$ spot volume to $440 \mathrm{pl}$ spot 


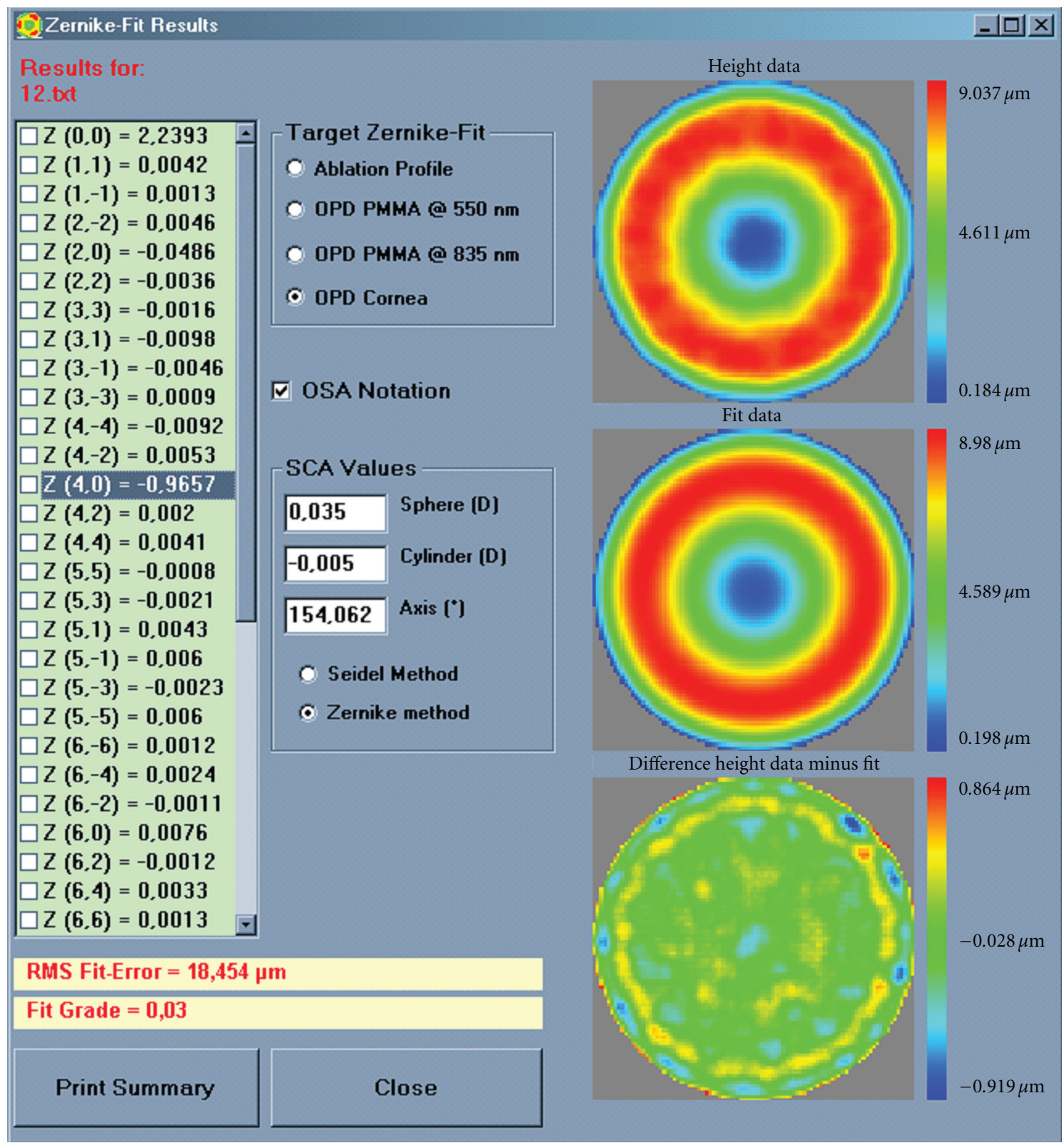

FIGURE 8: Ablation simulation of primary spherical aberration $Z[4,0]$, with $96,6 \%$ accuracy and $97 \%$ fit quality.

volume (corresponding to $90 \mathrm{~mJ} / \mathrm{cm}^{2}$ to $2000 \mathrm{~mJ} / \mathrm{cm}^{2}$ energy density, using as ablation volume the one corresponding to an aberration-free correction of $-5.00 \mathrm{D}-3.50 \mathrm{D} \times 15^{\circ}$ at $6.50 \mathrm{~mm} \mathrm{OZ}, 8.21 \mathrm{~mm}$ TAZ.

A second simulation was prepared upon the basis of a dual fluence level concept, using a variable rate from only low-fluence spots to only high-fluence spots using the same ablation volume for the correction of $-5.00 \mathrm{D}-3.50 \mathrm{D} \times 15^{\circ}$ at $6.50 \mathrm{~mm} \mathrm{OZ,} 8.21 \mathrm{~mm}$ TAZ.

With the optimal parameters we have evaluated the extent to which individual Zernike modes can be corrected, first simulated and then ablated onto flat PMMA plates.

\section{Results}

We have analysed ablation times and fidelity using fixed fluence levels ranging from $37 \mathrm{pl}$ spot volume to $440 \mathrm{pl}$ spot volume (corresponding to $90 \mathrm{~mJ} / \mathrm{cm}^{2}$ to $2000 \mathrm{~mJ} / \mathrm{cm}^{2}$ energy density, using as ablation volume the one corresponding to an aberration-free correction of $-5.00 \mathrm{D}-3.50 \mathrm{D} \times 15^{\circ}$ at $6.50 \mathrm{~mm} \mathrm{OZ}, 8.21 \mathrm{~mm}$ TAZ (Figure 4).

We have obtained as optimum fluence level a variable range from $105 \mathrm{pl}$ spot volume to $240 \mathrm{pl}$ spot volume, corresponding to $188 \mathrm{~mJ} / \mathrm{cm}^{2}$ to $565 \mathrm{~mJ} / \mathrm{cm}^{2}$ energy density with equivalent ablation time ranges from 60 seconds to 26 seconds, corresponding to $4.0 \mathrm{~s} / \mathrm{D}$ to $1.7 \mathrm{~s} / \mathrm{D}$ at $6 \mathrm{~mm} \mathrm{OZ}$ and 


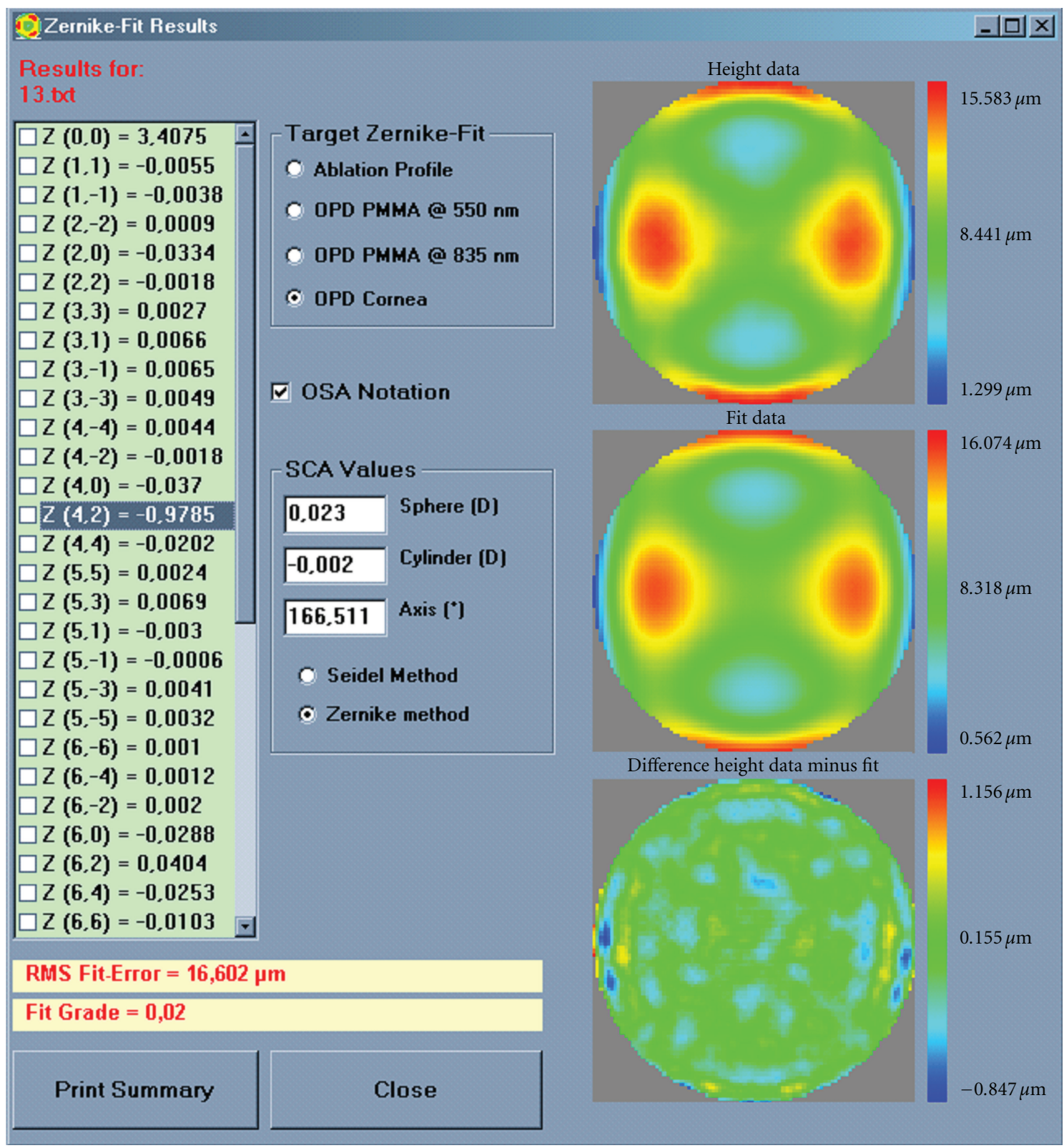

FIGURE 9: Ablation simulation of secondary astigmatism aberration $Z[4, \pm 2]$, with $97,9 \%$ accuracy and $98 \%$ fit quality.

equivalent fidelity variance from $50 \mu \mathrm{m}$ RMS to $60 \mu \mathrm{m}$ RMS and average ablation error from 0.475 to $0.575 \mu \mathrm{m}$ for each location (Table 1).

A second simulation was prepared upon the basis of a dual fluence level concept, using a variable rate from only low-fluence spots to only high-fluence spots using the same ablation volume for the correction of $-5.00 \mathrm{D}-3.50 \mathrm{D} \times 15^{\circ}$ at $6.50 \mathrm{~mm} \mathrm{OZ,} 8.21 \mathrm{~mm}$ TAZ (Figure 5).

We have obtained an optimum proportion range variable from $50 \%$ high fluence to $90 \%$ high fluence, with equivalent ablation time range from 45 seconds to 33 seconds,

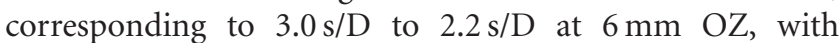
equivalent fidelity variance from $52 \mu \mathrm{m}$ RMS to $55 \mu \mathrm{m}$ RMS, and average ablation error from 0.490 to $0.525 \mu \mathrm{m}$ for each location (Table 2).

With the optimal parameters we have simulated the extent to which individual Zernike modes can be corrected (Figures 6, 7, 8, and 9, Table 3).

With the same parameters, we have evaluated the extent to which individual Zernike modes can be corrected, by ablating onto flat PMMA plates (Figures 10, 11, 12, and 13).

\section{Discussion}

We have evaluated to which extent individual Zernike terms can be corrected, by analysing ablation times and fidelity 


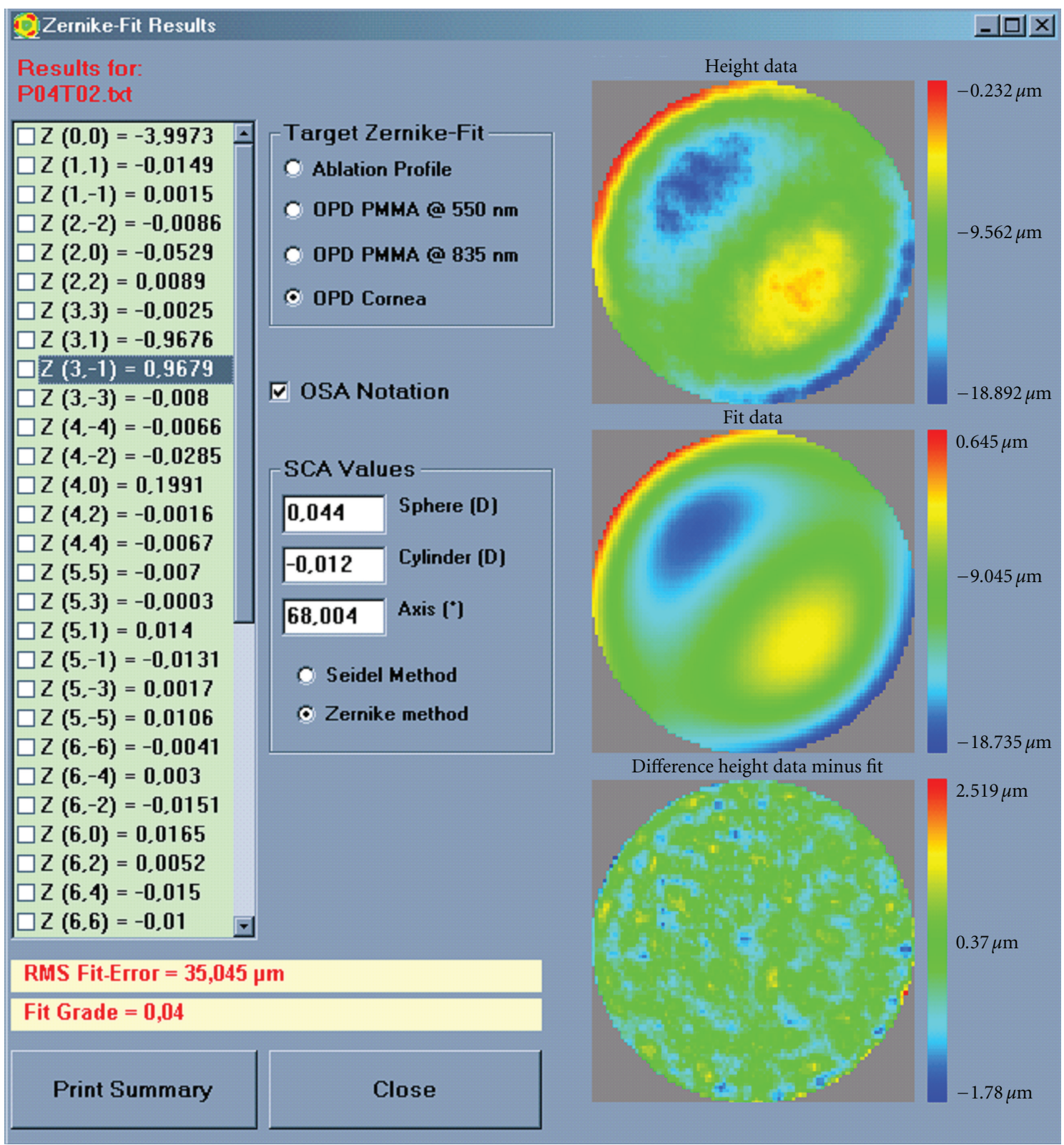

FIGURE 10: Ablation on a flat plate of PMMA of primary coma aberration Z[3, \pm 1$]$, with $96,7 \%$ accuracy and $96 \%$ fit quality.

using different fluence levels (range $90-2000 \mathrm{~mJ} / \mathrm{cm}^{2}$ ), and aspheric ablation profiles, as well as, using a dual fluence level concept (variable rate from only low fluence to only high fluence pulses). With the optimal parameters, the extent to which individual Zernike modes can be corrected was simulated and ablated onto PMMA with a laser.

Huang and Arif [16] investigated the effect of laser spot size on the outcome of aberration correction with scanning laser corneal ablation using numerical simulation of ablation outcome of correction of wavefront aberrations of Zernike modes from second to eighth order. They modeled gaussian and top-hat beams from 0.6 to $2.0 \mathrm{~mm}$ fullwidth-half-maximum diameters, evaluated the fractional correction and secondary aberration (distortion), and used a distortion/correction ratio of less than 0.5 as a cutoff for adequate performance. The found that a $2 \mathrm{~mm}$ or smaller beam is adequate for spherocylindrical correction (Zernike second order), a $1 \mathrm{~mm}$ or smaller beam is adequate for correction of up to fourth order Zernike modes, and a $0.6 \mathrm{~mm}$ or smaller beam is adequate for correction of up to sixth order Zernike modes.

Guirao et al. [17] calculated that the success of a customized laser surgery attempting to correct higher order aberrations depends on using a laser beam that is small enough to produce fine ablation profiles needed to correct higher order aberrations. Simulating more than 100 theoretical customized ablations performed with beams of $0.5,1.0,1.5$, and $2.0 \mathrm{~mm}$ in diameter, they calculated the 


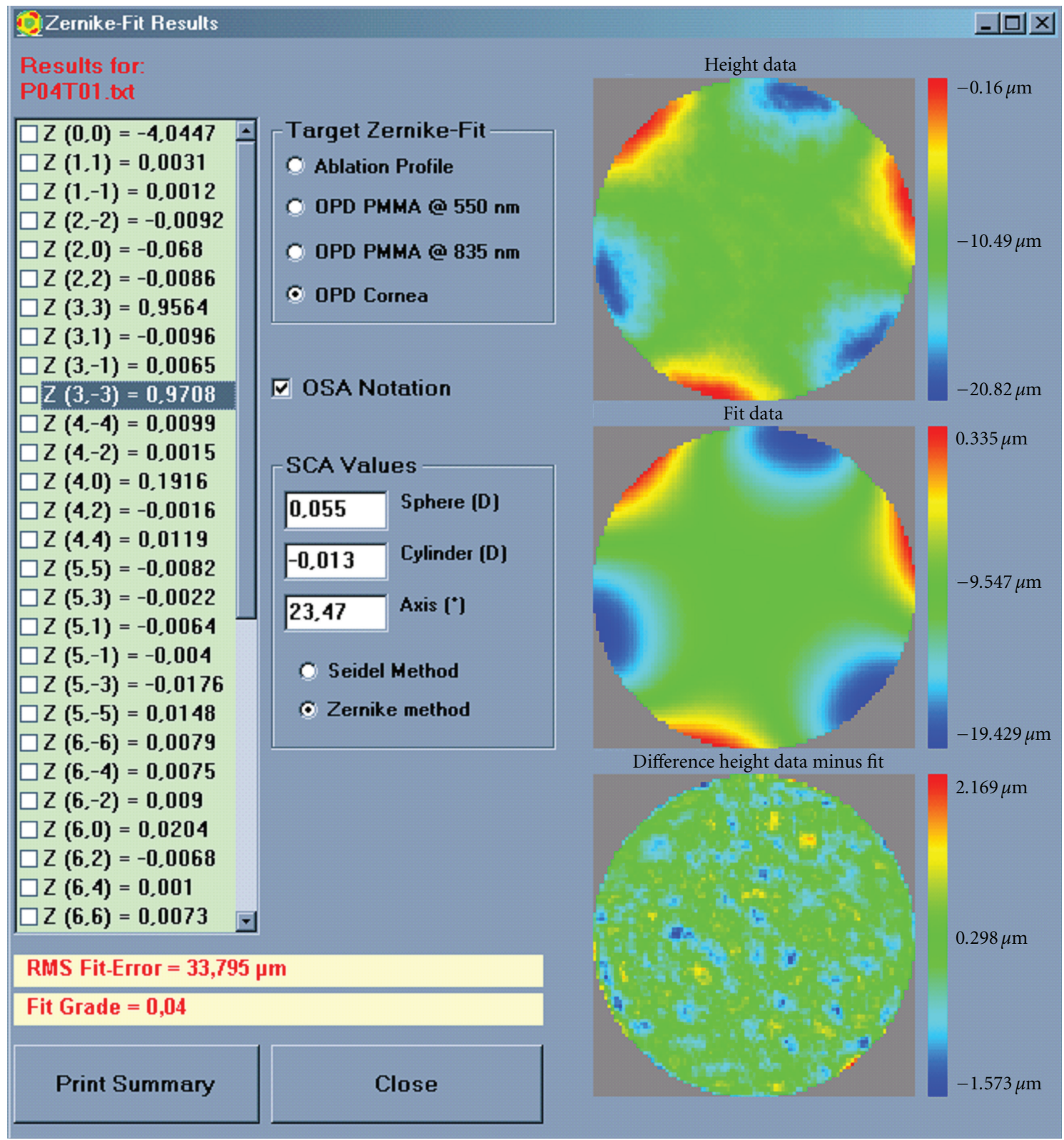

FIGURE 11: Ablation on a flat plate of PMMA of primary trefoil aberration Z[3, \pm 3$]$, with $97,1 \%$ accuracy and $96 \%$ fit quality.

residual aberrations remaining in the eye and estimated the modulation transfer function (MTF) from the residual aberrations. They found that the laser beam acts like a spatial filter, smoothing the finest features in the ablation profile and that the quality of the correction declines steadily when the beam size increases. A beam of $2 \mathrm{~mm}$ was capable of correcting defocus and astigmatism. Beam diameters of $1 \mathrm{~mm}$ or less may effectively correct aberrations up to fifth order.

Pettit [24] claimed that the LADARVision system using a small fixed diameter excimer laser beam providing a consistent ablation per pulse, is able to ablate complex (higher order) corneal shapes accurately.

As demonstrated by Pedder et al. [25] and Jiménez et al. [26], the incorporation of models taking into account the angular dependence of laser-ablation rates as well as the effect of plume absorption can be important in efforts to improve the ablation algorithms used in refractive surgery. Differences in corneal power and corneal asphericity encountered when using this model can significantly affect the visual function of patients after LASIK. The high accuracy of determination of stroma plume absorption coefficients and the incorporation of this information in laser-ablation equations can improve the prediction of postsurgical corneal shape. More accurate values for postsurgical radius and asphericity could be achieved and thereby enhance emmetropization and correction of eye aberrations in refractive surgery. However, in case of AMARIS, the effect of the ablation plume could be not so siginificant since a debris removal system is incorporated. 


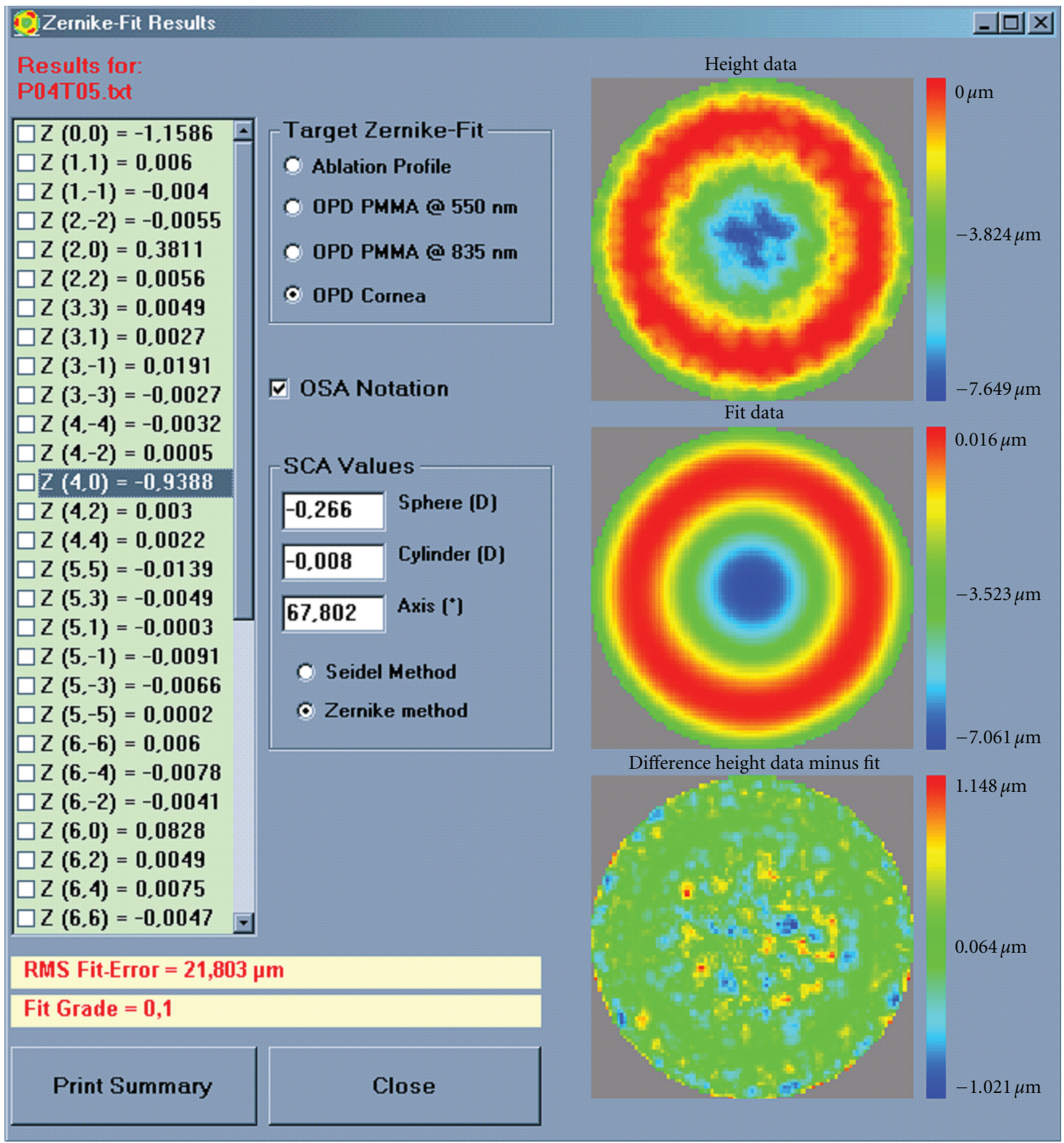

FIGURE 12: Ablation on a flat plate of PMMA of primary spherical aberration Z[4, 0], with 93,9\% accuracy and 90\% fit quality.

In our study, the range $188-565 \mathrm{~mJ} / \mathrm{cm}^{2}$ resulted as optimum fluence level for first simulation, and optimum proportion range $50 \%-90 \%$ high fluence for second one. With optimal parameters, it corresponds to $2.4 \mathrm{~s} / \mathrm{D}$ at $6 \mathrm{~mm} \mathrm{OZ}$, with fidelity variance of $53 \mu \mathrm{m}$ RMS, and average ablation error of $0.5 \mu \mathrm{m}$ for each location.

Ablation simulation of coma $Z[3, \pm 1]$, showed $98,4 \%$ accuracy, and $98 \%$ fit quality; trefoil $Z[3, \pm 3], 99,9 \%$ accuracy and $98 \%$ fit quality; spherical aberration $Z[4,0]$, $96,6 \%$ accuracy and $97 \%$ fit quality; secondary astigmatism $Z[4, \pm 2], 97,9 \%$ accuracy and $98 \%$ fit quality. Ablation on a flat plate of PMMA of coma Z[3, \pm 1$]$, showed $96,7 \%$ accuracy and $96 \%$ fit quality; trefoil $Z[3, \pm 3], 97,1 \%$ accuracy and $96 \%$ fit quality; spherical aberration $Z[4,0]$, with $93,9 \%$ accuracy and $90 \%$ fit quality; and secondary astigmatism $Z[4, \pm 2]$, with $96,0 \%$ accuracy and $96 \%$ fit quality.

The proposed dual fluence concept uses a high-fluence "HF" and a low-fluence "LF" level. HF to speed up the treatment (minimised ablation time), LF to ensure the highest accuracy (maximised ablation smoothness). In our simulations results, HF takes out $220 \mathrm{pl}$ vol per pulse $(725 \mathrm{~nm}$ peak depth per pulse) whereas LF removes $110 \mathrm{pl}$ vol per pulse ( $450 \mathrm{~nm}$ peak depth per pulse).

The amount of treatment that will receive HF pulses is optimised, to keep the overall quality of the ablation as good as possible (dynamically adjusted to speed up the treatment maintaining the highest accuracy). That means that 1 or 2 D will be made only by LF, but a higher diopter treatment 


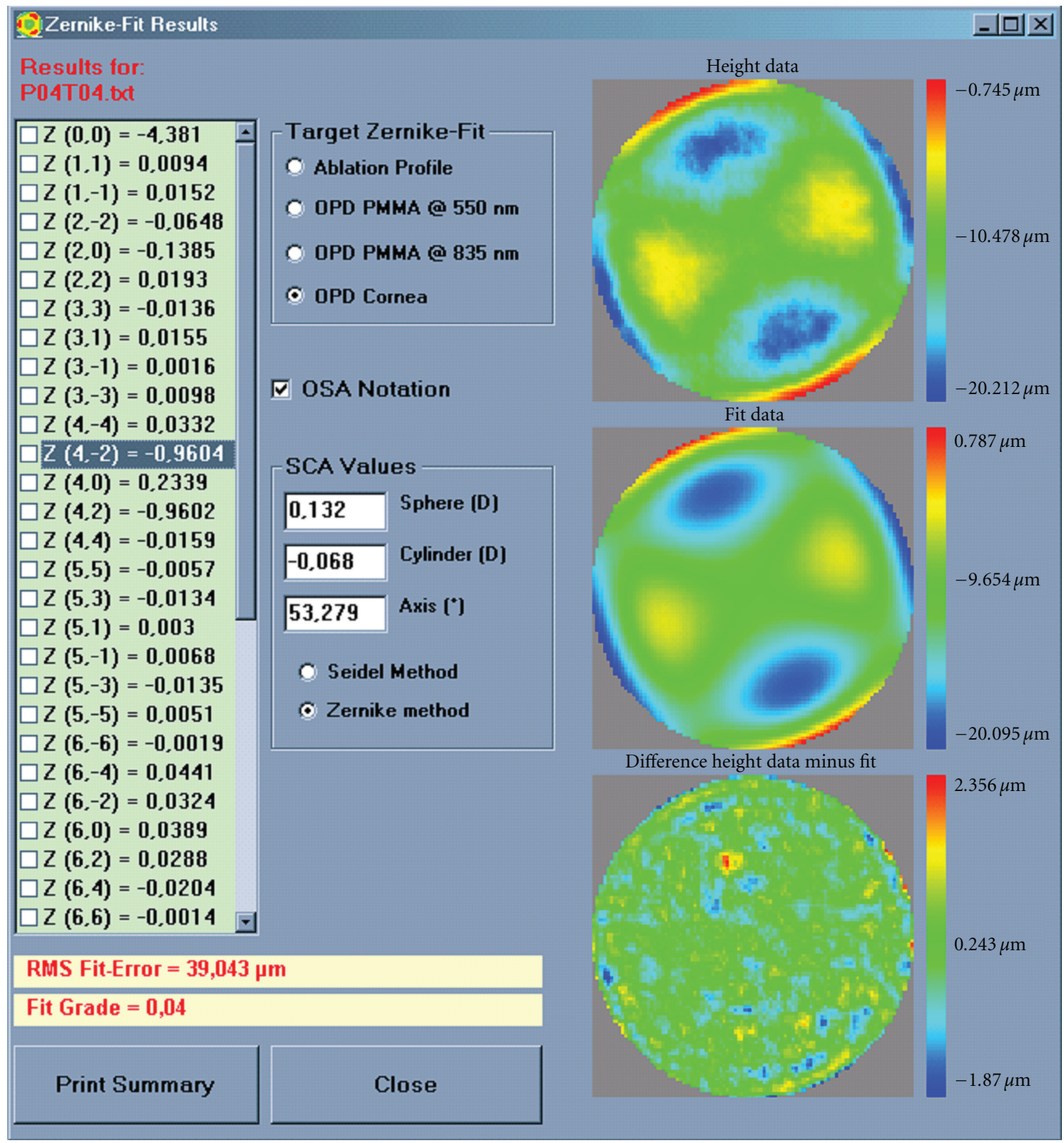

FIgURE 13: Ablation on a flat plate of PMMA of secondary astigmatism aberration Z[4, \pm 2$]$, with $96,0 \%$ accuracy and $96 \%$ fit quality.

will be made up to $95 \%$ with HF. Typically, about $80 \%$ of the ablation will be performed at HF.

The system uses the "automatic fluence level adjustment" procedure for optimal ablation control. Depending on the planned refractive correction, about 80 percent of the corneal ablation is performed with a high fluence level speeding up the treatment. Fine correction is performed with a low fluence level improving the resolution. The advantage is that the laser treatment is significantly shortened, especially when higher refractive corrections are involved-without compromising on precision and safety.

The analysis of the clinical results specifically addressing customized treatments will show whether there are corneal discrepancies between real and expected shapes. Clinical outcomes published up to now show consistent results [2730].

Ablation of aspherical and customised shapes based upon Zernike polynomials up the the 8th order seems accurate using the dual fluence concept implemented at the AMARIS platform.

In summary, this study demonstrated that it is possible to develop new algorithms and ablation strategies for efficiently performing laser corneal refractive surgery in a customised form. The availability of such profiles, potentially maximising visual performance without incresing the factors of risk, would be of great value for the refractive surgery community and ultimately for the health and safety of the patients. 
TABLE 3

\begin{tabular}{|c|c|c|c|c|c|}
\hline Zernike mode & Name & $\begin{array}{c}\text { Simulation } \\
\text { Accuracy (\%) }\end{array}$ & $\begin{array}{c}\text { Simulation } \\
\text { Fit quality }(\%)\end{array}$ & $\begin{array}{c}\text { PMMA } \\
\text { Accuracy (\%) }\end{array}$ & $\begin{array}{c}\text { PMMA } \\
\text { Fit quality (\%) }\end{array}$ \\
\hline $\mathrm{Z}[3, \pm 1]$ & Primary coma & 98,4 & 98 & 96,7 & 96 \\
\hline $\mathrm{Z}[3, \pm 3]$ & Primary trefoil & 99,9 & 98 & 97,1 & 96 \\
\hline $\mathrm{Z}[4,0]$ & Primary spherical aberration & 96,6 & 97 & 93,9 & 90 \\
\hline $\mathrm{Z}[4, \pm 2]$ & Secondary astigmatism & 97,9 & 98 & 96,0 & 96 \\
\hline $\mathrm{Z}[4, \pm 4]$ & Primary tetrafoil & 99,4 & 99 & 97,9 & 96 \\
\hline $\mathrm{Z}[5, \pm 1]$ & Secondary coma & 95,4 & 97 & 93,3 & 94 \\
\hline $\mathrm{Z}[5, \pm 3]$ & Secondary trefoil & 96,7 & 97 & 94,6 & 94 \\
\hline$Z[5, \pm 5]$ & Primary pentafoil & 99,1 & 99 & 97,0 & 96 \\
\hline $\mathrm{Z}[6,0]$ & Secondary spherical aberration & 96,0 & 95 & 93,9 & 92 \\
\hline$Z[6, \pm 2]$ & Tertiary astigmatism & 91,3 & 97 & 89,3 & 94 \\
\hline $\mathrm{Z}[6, \pm 4]$ & Secondary tetrafoil & 94,3 & 97 & 92,3 & 94 \\
\hline$Z[6, \pm 6]$ & Primary hexafoil & 99,0 & 98 & 96,9 & 95 \\
\hline $\mathrm{Z}[7, \pm 1]$ & Tertiary coma & 83,5 & 94 & 81,7 & 91 \\
\hline $\mathrm{Z}[7, \pm 3]$ & Tertiary trefoil & 86,5 & 95 & 84,6 & 92 \\
\hline$Z[7, \pm 5]$ & Secondary pentafoil & 93,0 & 96 & 91,0 & 93 \\
\hline $\mathrm{Z}[7, \pm 7]$ & Primary heptafoil & 98,5 & 98 & 96,4 & 95 \\
\hline $\mathrm{Z}[8,0]$ & Tertiary spherical aberration & 76,4 & 89 & 74,8 & 86 \\
\hline $\mathrm{Z}[8, \pm 2]$ & Eighth order astigmatism & 78,3 & 94 & 76,6 & 91 \\
\hline $\mathrm{Z}[8, \pm 4]$ & Tertiary tetrafoil & 80,8 & 94 & 79,1 & 91 \\
\hline$Z[8, \pm 6]$ & Secondary hexafoil & 90,0 & 95 & 88,1 & 92 \\
\hline $\mathrm{Z}[8, \pm 8]$ & Primary octafoil & 98,2 & 98 & 96,1 & 95 \\
\hline
\end{tabular}

Further clinical evaluations on human eyes are needed to confirm the preliminary simulated results presented herein.

\section{References}

[1] C. R. Munnerlyn, S. J. Koons, and J. Marshall, "Photorefractive keratectomy: a technique for laser refractive surgery," Journal of Cataract and Refractive Surgery, vol. 14, no. 1, pp. 46-52, 1988.

[2] L. Mastropasqua, L. Toto, E. Zuppardi et al., "Photorefractive keratectomy with aspheric profile of ablation versus conventional photorefractive keratectomy for myopia correction: six-month controlled clinical trial," Journal of Cataract and Refractive Surgery, vol. 32, no. 1, pp. 109-116, 2006.

[3] L. Buratto, M. Ferrari, and P. Rama, "Excimer laser intrastromal keratomileusis," American Journal of Ophthalmology, vol. 113, no. 3, pp. 291-295, 1992.

[4] I. G. Pallikaris and D. S. Siganos, "Excimer laser in situ keratomileusis and photorefractive keratectomy for correction of high myopia," Journal of Refractive and Corneal Surgery, vol. 10, no. 5, pp. 498-510, 1994.

[5] K. Ditzen, H. Huschka, and S. Pieger, "Laser in situ keratomileusis for hyperopia," Journal of Cataract and Refractive Surgery, vol. 24, no. 1, pp. 42-47, 1998.

[6] M. A. El Danasoury, G. O. Waring III, A. El Maghraby, and K. Mehrez, "Excimer laser in situ keratomileusis to correct compound myopic astigmatism," Journal of Refractive Surgery, vol. 13, no. 6, pp. 511-520, 1997.

[7] E. Moreno-Barriuso, J. M. Lloves, S. Marcos, R. Navarro, L. Llorente, and S. Barbero, "Ocular aberrations before and after myopic corneal refractive surgery: LASIK-induced changes measured with laser ray tracing," Investigative Ophthalmology and Visual Science, vol. 42, no. 6, pp. 1396-1403, 2001.

[8] L. N. Thibos, X. Hong, A. Bradley, and R. A. Applegate, "Accuracy and precision of objective refraction from wavefront aberrations," Journal of Vision, vol. 4, no. 4, pp. 329-351, 2004.

[9] T. O. Salmon, Corneal contribution to the Wavefront aberration of the eye, PhD Dissertation, 1999.

[10] M. Mrochen, M. Jankov, M. Bueeler, and T. Seiler, "Correlation between corneal and total wavefront aberrations in myopic eyes," Journal of Refractive Surgery, vol. 19, no. 2, pp. 104-112, 2003.

[11] J. L. Alió, J. I. Belda, A. A. Osman, and A. M. M. Shalaby, "Topography-guided laser in situ keratomileusis (TOPOLINK) to correct irregular astigmatism after previous refractive surgery," Journal of Refractive Surgery, vol. 19, no. 5, pp. 516-527, 2003.

[12] M. Mrochen, M. Kaemmerer, and T. Seiler, "Clinical results of wavefront-guided laser in situ keratomileusis 3 months after surgery," Journal of Cataract and Refractive Surgery, vol. 27, no. 2, pp. 201-207, 2001.

[13] M. Mrochen, C. Donitzky, C. Wüllner, and J. Löffler, "Wavefront-optimized ablation profiles: theoretical background," Journal of Cataract and Refractive Surgery, vol. 30, no. 4, pp. 775-785, 2004.

[14] T. Koller, H. P. Iseli, F. Hafezi, M. Mrochen, and T. Seiler, "Qfactor customized ablation profile for the correction of myopic astigmatism," Journal of Cataract and Refractive Surgery, vol. 32, no. 4, pp. 584-589, 2006.

[15] D. Gatinel, J. Malet, T. Hoang-Xuan, and D. T. Azar, "Analysis of customized corneal ablations: theoretical limitations of 
increasing negative asphericity," Investigative Ophthalmology and Visual Science, vol. 43, no. 4, pp. 941-948, 2002.

[16] D. Huang and M. Arif, "Spot size and quality of scanning laser correction of higher-order wavefront aberrations," Journal of Cataract and Refractive Surgery, vol. 28, no. 3, pp. 407-416, 2002.

[17] A. Guirao, D. R. Williams, and S. M. MacRae, "Effect of beam size on the expected benefit of customized laser refractive surgery," Journal of Refractive Surgery, vol. 19, no. 1, pp. 1523, 2003.

[18] M. Bueeler and M. Mrochen, "Simulation of eye-tracker latency, spot size, and ablation pulse depth on the correction of higher order wavefront aberrations with scanning spot laser systems," Journal of Refractive Surgery, vol. 21, no. 1, pp. 28-36, 2005.

[19] S. Marcos, D. Cano, and S. Barbero, "Increase in corneal asphericity after standard laser in situ keratomileusis for myopia is not inherent to the Munnerlyn algorithm," Journal of Refractive Surgery, vol. 19, no. 5, pp. S592-S596, 2003.

[20] M. Mrochen and T. Seiler, "Influence of corneal curvature on calculation of ablation patterns used in photorefractive laser surgery," Journal of Refractive Surgery, vol. 17, no. 5, pp. S584S587, 2001.

[21] J. R. Jiménez, R. G. Anera, L. Jiménez del Barco, and E. Hita, "Effect on laser-ablation algorithms of reflection losses and nonnormal incidence on the anterior cornea," Applied Physics Letters, vol. 81, no. 8, pp. 1521-1523, 2002.

[22] J. R. Jiménez, R. G. Anera, L. J. Del Barco, E. Hita, and F. Pérez-Ocón, "Correction factor for ablation algorithms used in corneal refractive surgery with gaussian-profile beams," Optics Express, vol. 13, no. 1, pp. 336-343, 2005.

[23] T. Bende, T. Seiler, and J. Wollensak, "Side effects in excimer corneal surgery. Corneal thermal gradients," Graefe's Archive for Clinical and Experimental Ophthalmology, vol. 226, no. 3, pp. 277-280, 1988.

[24] G. H. Pettit, "The Alcon/Summit/Autonomous perspective on fixed vs. variable spot ablation," Journal of Refractive Surgery, vol. 17, no. 5, pp. S592-S593, 2001.

[25] J. E. A. Pedder, A. S. Holmes, and P. E. Dyer, "Improved model for the angular dependence of excimer laser ablation rates in polymer materials," Applied Physics Letters, vol. 95, no. 17, Article ID 174105, 2009.

[26] J. R. Jiménez, J. J. Castro, C. Ortiz, and R. G. Anera, “Testing a model for excimer laser-ablation rates on corneal shape after refractive surgery," Optics Letters, vol. 35, p. 1789, 2010.

[27] M. C. Arbelaez and A. S. Mosquera, "The SCHWIND AMARIS total-tech laser as an all-rounder in refractive surgery," Middle East African Journal of Ophthalmology, vol. 16, no. 1, pp. 46-53, 2009.

[28] M. C. Arbelaez, I. M. Aslanides, C. Barraquer et al., "LASIK for myopia and astigmatism using the SCHWIND AMARIS excimer laser: an international multicenter trial," Journal of Refractive Surgery, vol. 26, no. 2, pp. 88-98, 2010.

[29] M. C. Arbelaez, T. Ewering, and S. A. Mosquera, "Decision assistant wizard to standardize optimal outcomes in excimer laser refractive corneal surgery," Journal of Refractive Surgery, vol. 25, pp. 1-11, 2010.

[30] M. Camellin and S. A. Mosquera, "Aspheric optical zones: the effective optical zone with the SCHWIND AMARIS," Journal of Refractive Surgery, vol. 19, pp. 1-12, 2010. 

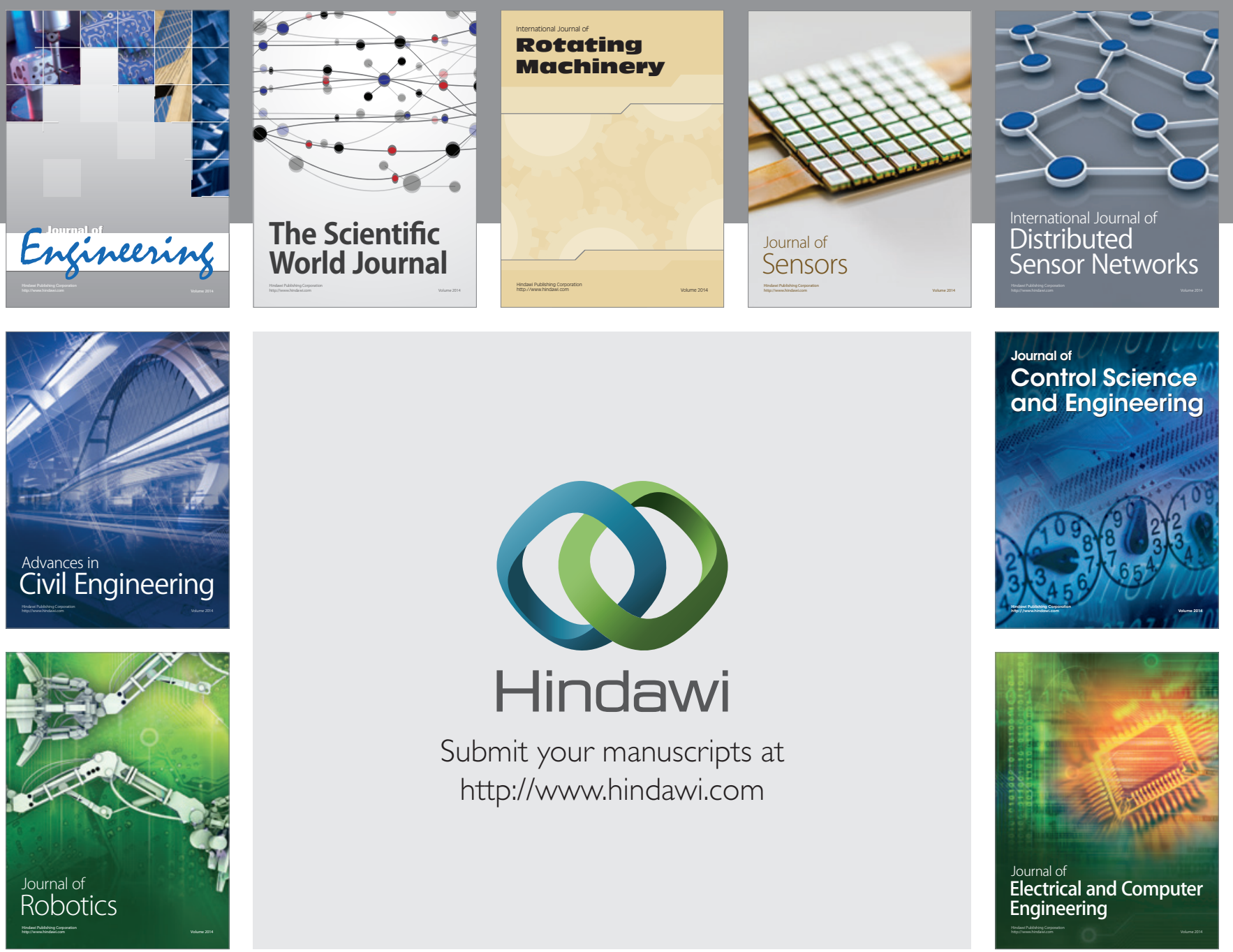

Submit your manuscripts at

http://www.hindawi.com
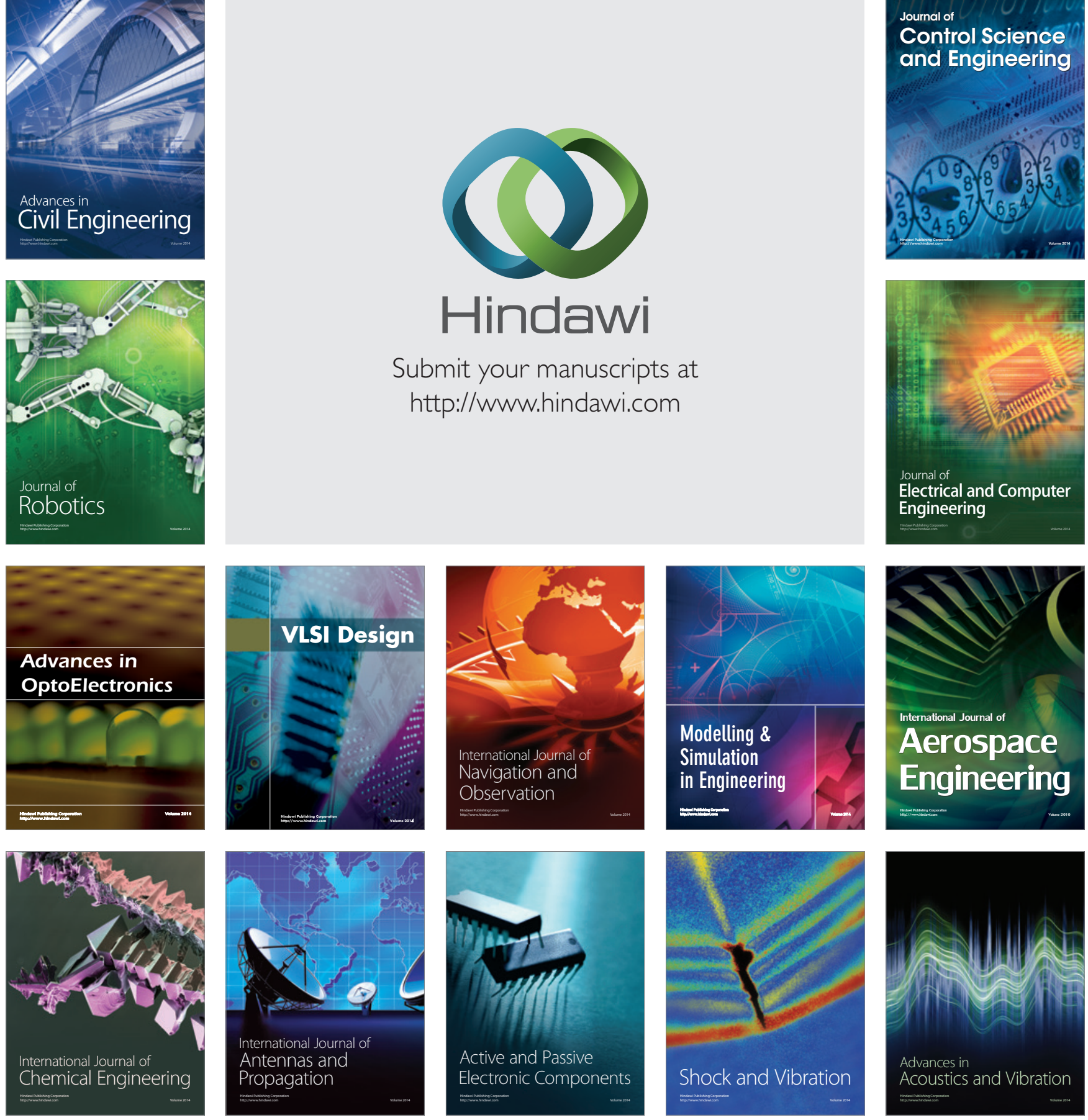